\title{
Crossroads in Classification: Comparison and Analysis of Fuzzy and Neuro-Fuzzy Techniques
}

\author{
Apoorvi Sood, Swati Aggarwal \\ ITM University \\ Gurgaon, India
}

\begin{abstract}
The paper introduces various methods for classification like fuzzy logic, and its combination with artificial neural networks. Datasets from UCI Repository have been used for the implementation of classification models using Matlab 7.0 for Fuzzy Inference System(FIS) and Anfis and Matlab R2007b for Anfis with variable labels and different membership functions.
\end{abstract}

\section{Keywords}

Classification Model, FIS, Anfis, Neuro Fuzzy Approach[1].

\section{INTRODUCTION}

We all know what classification is. It is actually deciding the output for a given input depending upon the attributes. It is a very important part of computational intelligence[14]. It refers to the idea of bionics and human understanding. A part of artificial intelligence is the soft computing techniques. It includes artificial neural networks, fuzzy logic, evolutionary algorithms and a hybrid approach of these. These techniques can be used alone but work the best in combination. Thus, we follow the cocktail approach of mixing these techniques together and getting better results.

This paper deals with the neuro fuzzy approach. The main advantage of using this combination is that the fuzzy logic makes the external environment understandable for the humans and improves adaptability while the artificial neural networks brings with it the learning. The neuro fuzzy approach used here is the ANFIS.

\subsection{Fuzzy Inference System}

Fuzzy logic[5] is a multi-valued logic derived from fuzzy set theory that deals with reasoning which is uncertain(approximate). It was a consequence of fuzzy set theory by Lofti Zadeh[9]. It has been widely used in the field of artificial intelligence and machine learning. The real world data is crisp in nature, that is, it can take values, 0 or 1 . The membership function maps the input data into fuzzy sets. This process is called fuzzification. The membership functions are linguistic variables. The fuzzy inference process[4] requires membership values to be combined with logical connectors and finally making if-then rules for classification.

The decision to be made requires construction of rules of the form:

$$
\text { IF input is ' } \mathrm{X} \text { ', THEN output is ' } \mathrm{Y} \text { ', }
$$

Where 'input' is the attribute for ' $\mathrm{X}$ ' membership function and 'output' is the class and ' $\mathrm{Y}$ ' is the decision finally made. Thus, input is the antecedent part and output forms the consequent part. For, consequent to be true, the antecedent must be true. The output that we get is defuzzified(converted back into crisp data) for the outside environment.

The Matlab7.0 provides with two FIS toolboxes: mamdani[10] type and sugeno[13] type. These two differ in their output. The former expects the output membership functions to be fuzzy sets, whereas the latter gives a linear or constant membership function as output. Mamdani is easy to work with and with fuzzy logic and its FIS, mamdani has been used.

\subsection{Artificial Neural Networks}

It is usually called Neural Networks. It is a mathematical or computational model inspired by the biological neural networks. It is similar in structure and functionalities. The network consists of an interconnected group of artificial neurons processing the information to compute the result. It is an adaptive system that changes its structure based on internal or external information that flows through it during the learning phase.

Classification[15] is possible because they model complex relationships between inputs and outputs by finding patterns. Artificial neurons[11] were first proposed by Warren McCulloch in 1943.

ANFIS[6] is a 5 layer feedforward adaptive network having square and circle nodes. The square nodes are adaptive because they have parameters while the circle nodes have none and are fixed. We get the desired output by updating the parameters according to the given training data and a learning procedure (backpropagation or hybrid).

\section{ORGANISATION OF THE PAPER}

Section 3 states the problem statement and related works. Section 4 gives an insight to the working datasets and section 5 shows the implementation of the work. Section 6 concludes the paper.

\section{PROBLEM STATEMENT AND RELATED WORK}

Since we need to deal with imprecise data, we use fuzzy inference system to implement a classification model and to make it better with adaptability, we use ANFIS.

The classification model categorizes the input into any of the output classes. It has been applied to real world data like Lenses dataset that helps the doctor to find which type of lenses suit the patient. Iris dataset has been used with both FIS and ANFIS. Also we have used different types of membership functions with varying labels to test our results.

Related works[7][8] have been carried out by many researchers. 


\section{WORKING DATASETS}

Iris dataset, Acute inflammations dataset and Lenses dataset from UCI repository have been used. FIS for Iris and Acute Inflammations dataset has been implemented. Iris dataset alongwith Lenses dataset has been used to work with Anfis.

\subsection{Iris Dataset}

It has 150 instances, 3 classes, each with 50 instances and 4 attributes.

Attributes: Sepal Length(SL); Sepal Width(SW); Petal Length(PL) and Petal Width(PW).

Classes: Setosa; Versicolor and Virginica.

\subsection{Acute Inflammations Dataset}

It has 120 instances, 3 classes and 6 attributes.

Attributes: Temperature(T); Nausea(NS); Lumbar Pain(LP); Urine Pushing(UP); Mictuirition Pains(MP) and Burning(B).

Classes: Inflammation of Urinary Bladder(IUB); Nephritis(NN) and Normal(NR).

\subsection{Lenses Dataset}

It has 24 instances, 3 classes and 4 attributes.

Attributes: Age of the patient: (1) young, (2) pre-presbyopic, (3) presbyopic; Spectacle prescription: (1) myope, (2) hypermetrope; Astigmatic: (1) no, (2) yes and Tear production rate: (1) reduced, (2) normal.

Classes: the patient should be fitted with hard contact lenses; the patient should be fitted with soft contact lenses and the patient should not be fitted with contact lenses.

\section{EXAMPLE}

\subsection{Iris Dataset}

This dataset has been used with 3 different techniques, FIS, degree of weighted convenience and Anfis. Matlab's toolbox for fuzzy logic has been used for its implementation using Fis and Anfis.

The method of degree of weighted convenience is employed with variable labels(5,7,9,11 and 13), forming definitive rules for each class and assigning some weight to the rule which determines the class for the instance being tested.

Table 1: Variable Labels

\begin{tabular}{|c|l|}
\hline Labels & \multicolumn{1}{|c|}{ SL } \\
\hline 3 & L,M,H \\
\hline 5 & VL,L,M,H,VH \\
\hline 7 & VL,ML,L,M,H,MH,VH \\
\hline 9 & PL,VL,ML,L,M,H,VH,PH \\
\hline 11 & ZL,NL,PL,VL,L,M,H,VH,PH,NH,ZH \\
\hline 13 &
\end{tabular}

The other three attributes, SW,PL and PW also have the same labels. The labels are 'L' for 'Low', 'H' for 'High', ' $M$ ' for 'Medium', 'V' for 'Very', 'P' for 'Positive', ' $Z$ ' for 'Zero' and ' $\mathrm{N}$ ' for 'Negative'. Triangular membership functions have been used. Once the number of labels is decided, we pick the data for training and make the rules.

Lets consider 5 labels for Iris dataset. For ease, lets take 15 instances, 5 of each of the three classes. The following table lists the training data:

Table 2: Training Set for Iris Dataset

\begin{tabular}{|l|l|l|}
\hline Setosa & Versicolor & Virginica \\
\hline $4.6,3.4,1.4,0.3$ & $6.6,2.9,4.6,1.3$ & $6.1,3,4.9,1.8$ \\
\hline $5.7,3.8,1.7,0.3$ & $5,2,3.5,1$ & $6.1,2.6,5.6,1.4$ \\
\hline $5.2,3.4,1.4,0.2$ & $6.2,2.2,4.5,1.5$ & $6.9,3.1,5.4,2.1$ \\
\hline $4.5,2.3,1.3,0.3$ & $5.9,3.2,4.8,1.8$ & $6.7,3.1,5.6,2.4$ \\
\hline $4.4,3.2,4.4,0.2$ & $6,2.9,4.5,1.5$ & $6.2,3.4,5.4,2.3$ \\
\hline
\end{tabular}

We can form the rules as follows:

Consider, datum 1 of class Setosa, ((4.6,3.4,1.4,0.3),1), the value 4.6 for sepal length can be mapped with label VL, 3.4 with M, 1.4 with VL and 0.3 with VL. Thus we have the rule $((\{\mathrm{VL}\},\{\mathrm{M}\},\{\mathrm{VL}\},\{\mathrm{VL}\}), 1)$ for this datum. Similarly all the instances can be mapped with labels to form rules. The following table gives the rules corresponding to these data values:

Table 3: Rules for Training dataset

\begin{tabular}{|l|l|l|}
\hline \multicolumn{1}{|c|}{ Setosa } & \multicolumn{1}{|c|}{ Versicolor } & \multicolumn{1}{c|}{ Virginica } \\
\hline $\begin{array}{l}((\{\mathrm{VL}\},\{\mathrm{M}\},\{\mathrm{VL}\} \\
,\{\mathrm{VL}\}), 1)\end{array}$ & $((\{\mathrm{H}\},\{\mathrm{L}\},\{\mathrm{H}\},\{$ & $((\{\mathrm{M}\},\{\mathrm{M}\},\{\mathrm{H}\}$, \\
& $\mathrm{M}\}), 2)$ & $\{\mathrm{H}\}), 3)$ \\
\hline$((\{\mathrm{L}\},\{\mathrm{H}\},\{\mathrm{VL}\},\{$ & $((\{\mathrm{VL}\},\{\mathrm{VL}\},\{$ & $((\{\mathrm{M}\},\{\mathrm{L}\},\{\mathrm{H}\}$, \\
$\mathrm{VL}\}), 1)$ & $\mathrm{M}\},\{\mathrm{L}\}), 2)$ & $\{\mathrm{M}\}), 3)$ \\
\hline$((\{\mathrm{L}\},\{\mathrm{M}\},\{\mathrm{VL}\},\{$ & $((\{\mathrm{M}\},\{\mathrm{VL}\},\{\mathrm{M}$ & $((\{\mathrm{H}\},\{\mathrm{M}\},\{\mathrm{H}\}$, \\
$\mathrm{VL}\}), 1)$ & \}$,\{\mathrm{M}\}), 2)$ & $\{\mathrm{VH}\}), 3)$ \\
\hline $\begin{array}{l}((\{\mathrm{VL}\},\{\mathrm{VL}\},\{\mathrm{VL} \\
\},\{\mathrm{VL}\}), 1)\end{array}$ & $((\{\mathrm{M}\},\{\mathrm{M}\},\{\mathrm{H}\}$, & $((\{\mathrm{H}\},\{\mathrm{M}\},\{\mathrm{H}\}$, \\
& $\{\mathrm{H}\}), 2)$ & $\{\mathrm{VH}\}), 3)$ \\
\hline$((\{\mathrm{VL}\},\{\mathrm{M}\},\{\mathrm{VL}\}$ & $((\{\mathrm{M}\},\{\mathrm{L}\},\{\mathrm{M}\}$, & $((\{\mathrm{M}\},\{\mathrm{M}\},\{\mathrm{H}\}$, \\
$,\{\mathrm{VL}\}), 1)$ & $\{\mathrm{M}\}), 2)$ & $\{\mathrm{VH}\}), 3)$ \\
\hline
\end{tabular}

The numbers $1,2,3$ specify the class the data value belongs to. As stated by Castro [1], if the output of two rules is same then both these rules can be merged and a definitive rule can be formed. The following rules are the final definitive rules formed for each class:

Class Setosa: Ro: ((\{VL,L\}, $\{\mathrm{VL}, \mathrm{M}, \mathrm{H}\},\{\mathrm{VL}\},\{\mathrm{VL}\}), 1)$.

Class Versicolor: $\mathrm{R}_{1}$ :

(( $\{\mathrm{VL}, \mathrm{M}, \mathrm{H}\},\{\mathrm{VL}, \mathrm{L}, \mathrm{M}\},\{\mathrm{M}, \mathrm{H}\},\{\mathrm{L}, \mathrm{M}, \mathrm{H}\}), 2)$.

Class Virginica: $\mathrm{R}_{2}:((\{\mathrm{M}, \mathrm{H}\},\{\mathrm{L}, \mathrm{M}\},\{\mathrm{H}\},\{\mathrm{M}, \mathrm{H}, \mathrm{VH}\}), 3)$.

We get the classification result as output of the fuzzy rule that has the maximal value of degree of weighted convenience for 
which the formula is: The degree of weighted convenience is calculated by:
$\mathrm{R}=\Sigma \Psi_{\mathrm{Li}}$
$\left(\mathrm{x}_{\mathrm{i}}\right)$
$*$
$\mathrm{w}_{\mathrm{i}}$

(1)

for $\mathrm{i}=1$ to $\mathrm{n}$

where $\Psi_{\mathrm{Li}}\left(\mathrm{x}_{\mathrm{i}}\right)$

is the degree of membership of $\mathrm{x}_{\mathrm{i}}$ in label $\mathrm{L}_{\mathrm{i}}$.

For this we find the complete range of each attribute for all the three classes and then individual range of each attribute in a class which is non overlapping. This process can be applied to test the data. For testing instance, $(4.7,3.2,1.3,0.2)$, we map the data values into $(\{\mathrm{VL}\},\{\mathrm{M}\},\{\mathrm{VL}\},\{\mathrm{VL}\})$ and we can see that it subsumes into Ro. thus this datum belongs to class Setosa. Consider another instance, $(4.4,2.9,1.4,0.2)$ which can be mapped as $(\{\mathrm{VL}\},\{\mathrm{L}\},\{\mathrm{VL}\},\{\mathrm{VL}\})$. This cannot be subsumed in any of the three rules. Here we calculate the weighted convenience using the following formulae as follows:

$\mathrm{v}_{\mathrm{i}}=\mathrm{N} \cdot \mathrm{O} \cdot \mathrm{D} / \mathrm{range}$

where N.O.D is the non overlapping domain for each attribute and range is the complete domain of the attribute and vi is the individual domain for attribute $i$.

Following values are derived for the above instance:

$\mathrm{v}_{1}=0.52, \mathrm{v}_{2}=0.39, \mathrm{v}_{3}=1, \mathrm{v}_{4}=0.73$;

To calculate the weight of each rule(wi), the following formula is used:

$\mathrm{w}_{\mathrm{i}}=\left(\mathrm{v}_{\mathrm{i}} / \max \left(\mathrm{v}_{1}, \mathrm{v}_{2}, \ldots ., \mathrm{v}_{\mathrm{n}}\right)\right)^{2}$

$\mathrm{w}_{1}=0.27, \mathrm{w}_{2}=0.15, \mathrm{w}_{3}=1, \mathrm{w}_{4}=0.54$;

After obtaining these values, we calculate the membership of the instance in each rule as:

$\Psi_{01}(4.4)=1$,

$\Psi_{02}(2.9)=0$,

$\Psi_{03}(1.4)=1$,

$\Psi_{04}(0.2)=1$.

The weighted convenience for rule $\mathrm{R}_{0}$ is calculated as:

$0.27 * 1+0.15 * 0+1 * 1+0.54 * 1=1.81$

Similarly weighted convenience for other two rules can also be calculated. $\mathrm{R}_{0}=1.81, \mathrm{R}_{1}=0, \mathrm{R}_{2}=0.15$. Since, rule $\mathrm{R}_{0}$ has the maximum value, this testing instance belongs to class Setosa. Similarly, these steps can be performed for all number of labels.

The Fis implementation is done with 3 labels and triangular membership functions. There are a total of 16 rules.

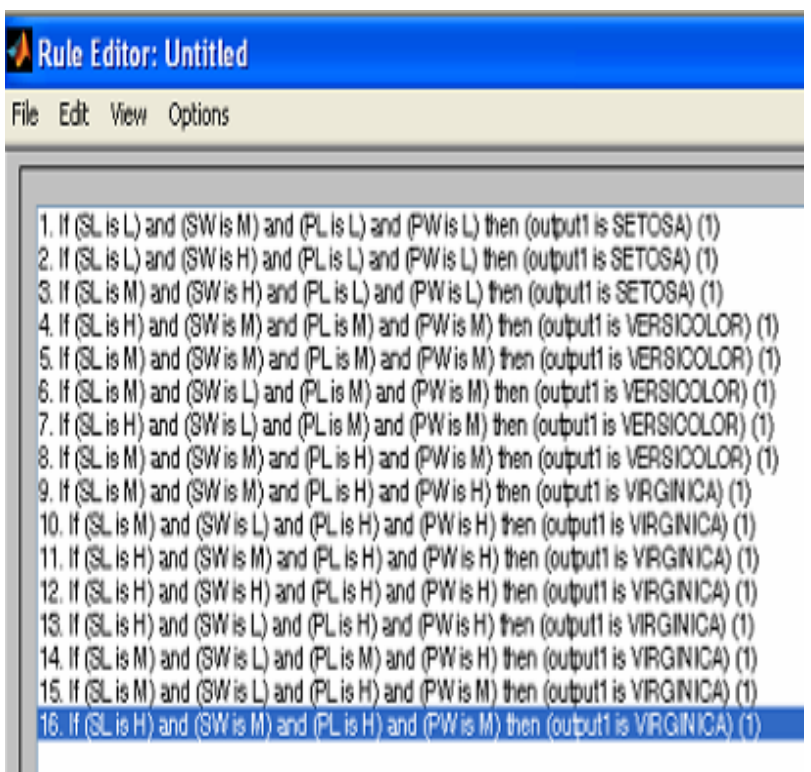

Fig 1: Rules for Iris dataset

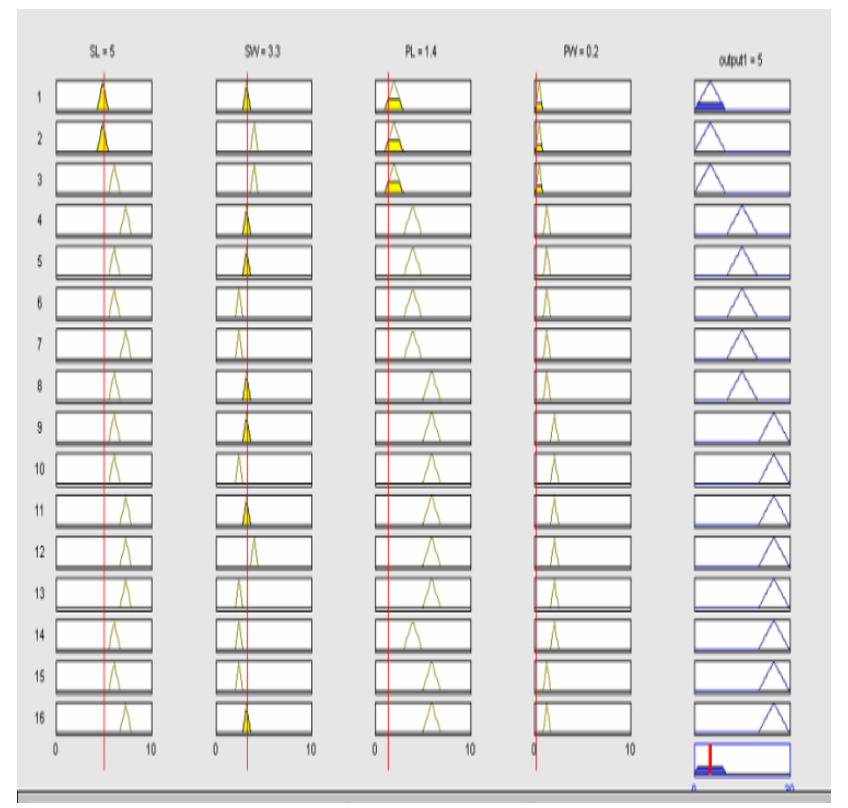

Fig 2: Testing instance 50(Class Setosa)

For the Anfis implementation, the first 30 instances of each class forms the training dataset(90) and the remaining instances form the testing dataset(60). It has also been implemented using 3 and 5 labels each with triangular and Gaussian bell membership function. 


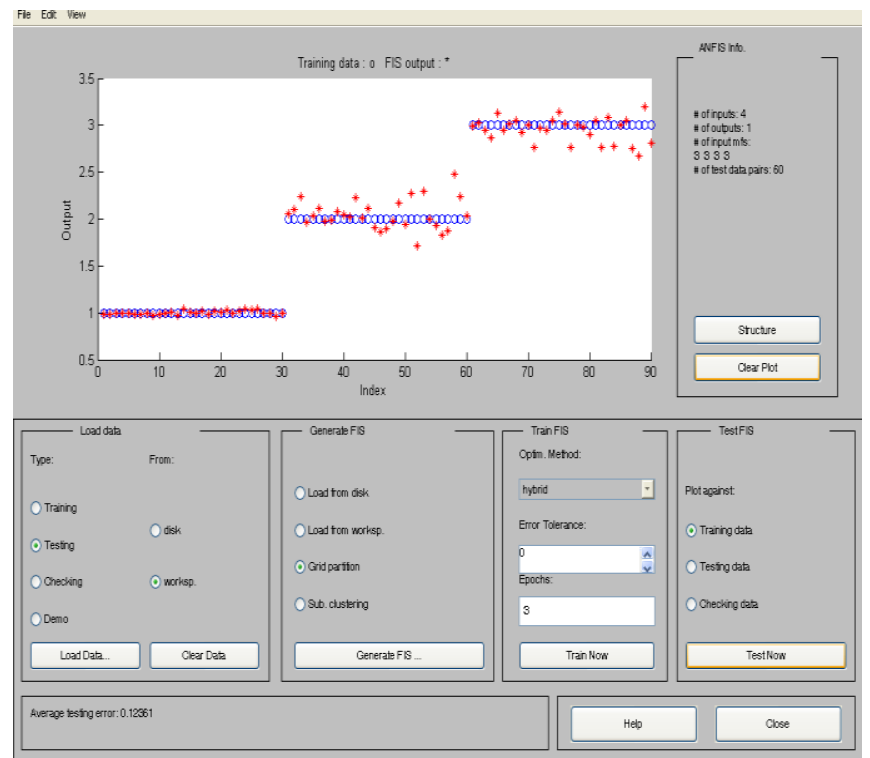

Fig 3: 3 labels with Triangular membership functions

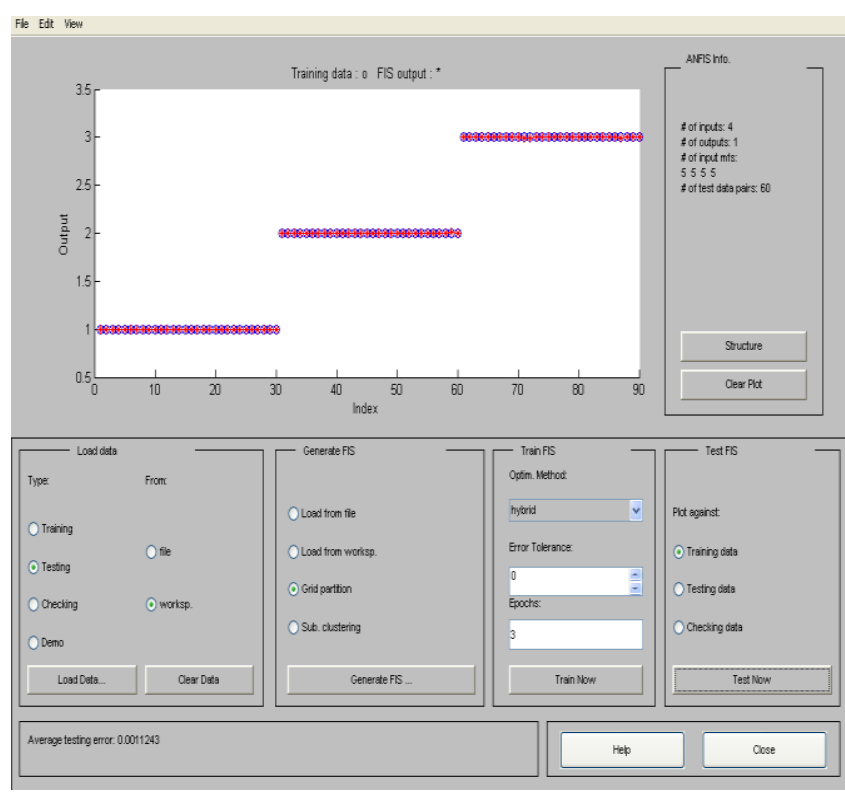

Fig 4: 5 labels with Gaussian bell membership function

\subsection{Acute Inflammations Dataset}

72 instances were used to train the model and 48 instances formed the testing set. We have the following rules for each class:

Table 4: Rules for Acute Inflammations dataset

\begin{tabular}{|l|l|l|}
\hline \multicolumn{1}{|c|}{ IUB } & \multicolumn{1}{|c|}{$\mathrm{NP}$} & \multicolumn{1}{c|}{$\mathrm{NR}$} \\
\hline$((\{\mathrm{L}\},\{\mathrm{N}\},\{\mathrm{N}\},\{$ & $((\{\mathrm{M}\},\{\mathrm{N}\},\{\mathrm{Y}\},\{$ & $((\{\mathrm{L}\},\{\mathrm{N}\},\{\mathrm{Y}\},\{$ \\
$\mathrm{Y}\},\{\mathrm{Y}\},\{\mathrm{Y}\}) 1)$ & $\mathrm{Y}\},\{\mathrm{N}\},\{\mathrm{Y}\}) 2)$ & $\mathrm{N}\},\{\mathrm{N}\},\{\mathrm{N}\}) 3)$ \\
\hline$((\{\mathrm{L}\},\{\mathrm{N}\},\{\mathrm{N}\},\{$ & $((\{\mathrm{H}\},\{\mathrm{N}\},\{\mathrm{Y}\},\{$ & $((\{\mathrm{M}\},\{\mathrm{N}\},\{\mathrm{Y}\},\{$ \\
$\mathrm{Y}\},\{\mathrm{Y}\},\{\mathrm{N}\}) 1)$ & $\mathrm{Y}\},\{\mathrm{N}\},\{\mathrm{Y}\}) 2)$ & $\mathrm{N}\},\{\mathrm{N}\},\{\mathrm{N}\}) 3)$ \\
\hline$((\{\mathrm{L}\},\{\mathrm{N}\},\{\mathrm{N}\},\{$ & $((\{\mathrm{H}\},\{\mathrm{Y}\},\{\mathrm{Y}\},\{$ & $((\{\mathrm{H}\},\{\mathrm{N}\},\{\mathrm{N}\},\{$ \\
\hline
\end{tabular}

\begin{tabular}{|l|l|l|}
\hline $\mathrm{Y}\},\{\mathrm{N}\},\{\mathrm{N}\}) 1)$ & $\mathrm{N}\},\{\mathrm{Y}\},\{\mathrm{N}\}) 2)$ & $\mathrm{N}\},\{\mathrm{N}\},\{\mathrm{N}\}) 3)$ \\
\hline$((\{\mathrm{M}\},\{\mathrm{N}\},\{\mathrm{N}\},\{$ & & \\
$\mathrm{Y}\},\{\mathrm{Y}\},\{\mathrm{Y}\}) 1)$ & & \\
\hline$((\{\mathrm{M}\},\{\mathrm{N}\},\{\mathrm{N}\},\{$ & & \\
$\mathrm{Y}\},\{\mathrm{Y}\},\{\mathrm{N}\}) 1)$ & & \\
\hline$((\{\mathrm{M}\},\{\mathrm{N}\},\{\mathrm{N}\},\{$ & & \\
$\mathrm{Y}\},\{\mathrm{N}\},\{\mathrm{N}\}) 1)$ & & \\
\hline$((\{\mathrm{H}\},\{\mathrm{Y}\},\{\mathrm{Y}\},\{$ & & \\
$\mathrm{Y}\},\{\mathrm{Y}\},\{\mathrm{Y}\}) 1)$ & & \\
\hline$((\{\mathrm{H}\},\{\mathrm{Y}\},\{\mathrm{Y}\},\{$ & & \\
$\mathrm{Y}\},\{\mathrm{Y}\},\{\mathrm{N}\}) 1)$ & & \\
\hline
\end{tabular}

Instance $(37.4, \mathrm{~N}, \mathrm{Y}, \mathrm{N}, \mathrm{N}, \mathrm{N})$ can be mapped into $(\{\mathrm{L}\},\{\mathrm{N}\},\{\mathrm{Y}\},\{\mathrm{N}\},\{\mathrm{N}\},\{\mathrm{N}\})$ which belongs to class Normal that is, the patient is normal. This can be repeated for all testing data. The following snapshot shows the testing of an instance:

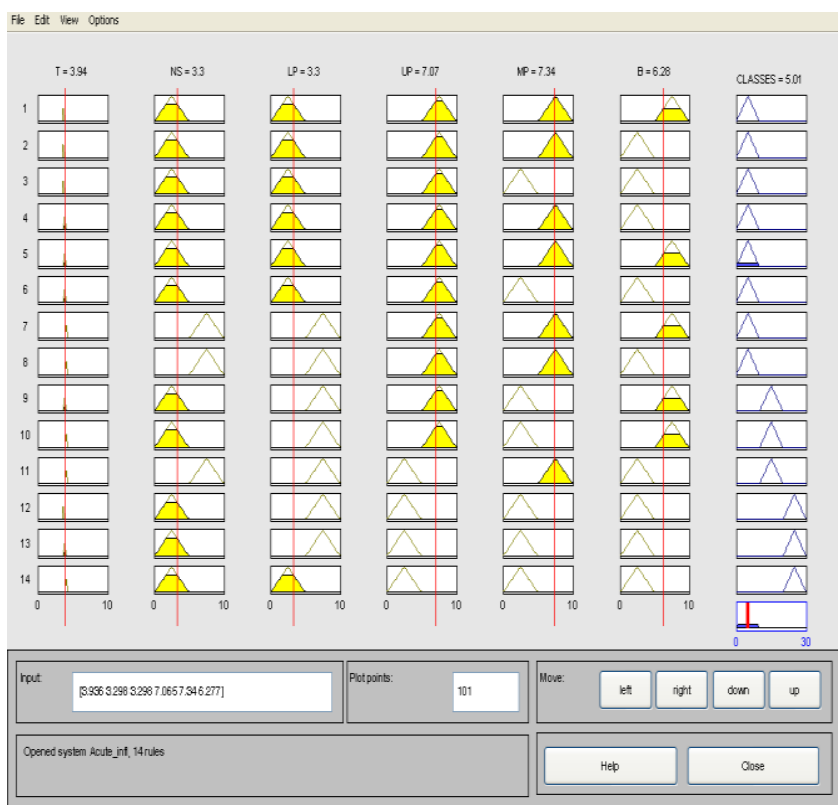

Fig 5: Testing of instance 39(class IUB)

\subsection{Lenses Dataset}

There are total 14 rules for training dataset having 14 instances and 10 instances are used for testing the classification model using ANFIS. There are no overlapping rules. Rules are given as follows:

Table 5: Rules for Lenses dataset

\begin{tabular}{|c|c|c|}
\hline HR & S & \multicolumn{1}{c|}{ N } \\
\hline$\{\{\mathrm{M}, \mathrm{L}, \mathrm{H}, \mathrm{H}\}, 1\}$ & $\{\{\mathrm{M}, \mathrm{L}, \mathrm{L}, \mathrm{H}\}, 2\}$ & $\{\{\mathrm{L}, \mathrm{L}, \mathrm{L}, \mathrm{L}\}, 3\}$ \\
\hline$\{\{\mathrm{H}, \mathrm{L}, \mathrm{H}, \mathrm{H}\}, 1\}$ & $\{\{\mathrm{M}, \mathrm{H}, \mathrm{L}, \mathrm{H}\}, 2\}$ & $\{\{\mathrm{L}, \mathrm{H}, \mathrm{L}, \mathrm{L}\}, 3\}$ \\
\hline & $\{\{\mathrm{H}, \mathrm{H}, \mathrm{L}, \mathrm{H}\}, 2\}$ & $\{\{\mathrm{M}, \mathrm{L}, \mathrm{L}, \mathrm{L}\}, 3\}$ \\
\hline & & $\{\{\mathrm{M}, \mathrm{L}, \mathrm{H}, \mathrm{L}\}, 3\}$ \\
\hline
\end{tabular}




\begin{tabular}{|l|l|l|}
\hline & & $\{\{\mathrm{M}, \mathrm{H}, \mathrm{H}, \mathrm{L}\}, 3\}$ \\
\hline & & $\{\{\mathrm{M}, \mathrm{H}, \mathrm{H}, \mathrm{H}\}, 3\}$ \\
\hline & & $\{\{\mathrm{H}, \mathrm{L}, \mathrm{L}, \mathrm{H}\}, 3\}$ \\
\hline & & $\{\{\mathrm{H}, \mathrm{L}, \mathrm{H}, \mathrm{L}\}, 3\}$ \\
\hline & & $\{\{\mathrm{H}, \mathrm{H}, \mathrm{H}, \mathrm{L}\}, 3\}$ \\
\hline
\end{tabular}

Here, 'L' stands for 'Low', 'M' for 'Medium', 'H' for 'High', 'HR' for 'Hard Contact lenses', 'S' for 'Soft Contact lenses', and ' $\mathrm{N}$ ' for 'No contact lenses'.

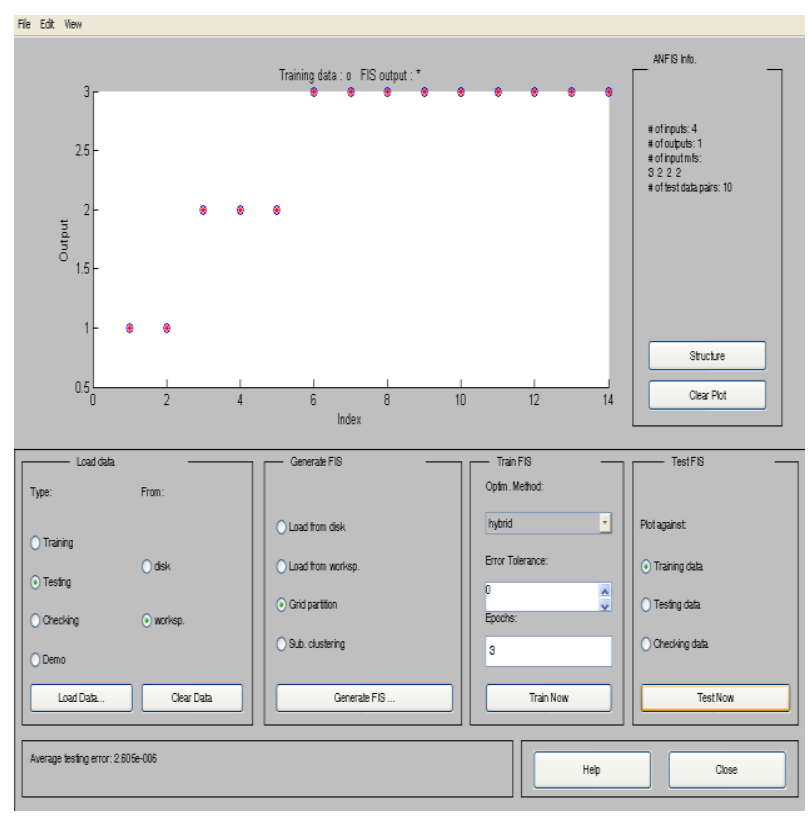

Fig 6: Average testing error for Lenses Dataset

\section{CONCLUSION}

On comparing both the Iris and Acute inflammations datasets, we find that numeric, unmapped data is more flexible because we can use many number of labels and check the accuracy with it. Also, there was discrepancy in results of 2 instances when consulted the doctor[2] for Acute Inflammations dataset. With increase in number of labels the range becomes more clearer and also the number of rules increases. For 11 labels, the average accuracy rate is the maximum for Iris Dataset. It has been found that the method of weighted convenience is better than FIS because there are some overlapping rules in FIS whereas, in the weighted convenience method there are no overlapping rule because each rule has some weight for the corresponding instance and the maximum weight decides the rule to which the instance belongs.

The Iris dataset when used for Anfis classifier, it was found that classification using neural networks along with fuzzy logic is better because we can adapt the system and then use it accordingly. We cannot keep on increasing the epochs because it leads to overtraining and increases the error rate drastically.

We get the best classification results with 5 labels. When we change the membership function from triangular to Gaussian bell, the classification improves drastically. Thus, using 5 labels with Gaussian bell membership function, we get the best results with Anfis implementation.

Mamdani fis cannot be trained because we are able to see the membership functions and view the change in results. But with the Sugeno fis we can train the system with artificial neural networks. This is needed because there are some parameters like premise parameters and consequent parameters which can be trained by any learning algorithms. The Anfis generates a fis for the data which can be manipulated according to the requirements.

\section{REFERENCES}

[1] Ajith Abraham, "Neuro Fuzzy Systems: State-of-the-art Modeling Techniques".

[2] Dr. Rajeev Sood, M.ch Uro Surgery, Sr. Uro Surgeon, Dr. R.M.L.Hospital, New Delhi-110001.

[3] Machine Learning and Intelligent Systems available at: http://archive.ics.uci.edu/ml/datasets.html .

[4] Fuzzy control system available

at: http://en.wikipedia.org/wiki/Fuzzy_control_system.

[5] Fuzzy logic available at: http://en.wikipedia.org/wiki/Fuzzy_logic.

[6] Jang, "ANFIS: adaptive Network-Based Fuzzy Inference System”, MAY/JUNE 1993, IEEE.

[7] J.L. Castro and J.M. Zurita, "An Inductive Learning Algorithm In Fuzzy Systems".

[8] J.L. Castro, J.J. Castro-Schez, J.M. Zurita, "Learning maximal Structure Rules in Fuzzy Logic for Knowledge Acquisition in expert systems".

[9] L.A. Zadeh, Fuzzy sets, Inform. and Control 8 (1965) 338353.

[10] Mamdami, E.H.; Assilina, S., "An experiment in linguistic synthesis with a fuzzy logic controller", International Journal of Man-Machine Studies, vol. 7(1), pp. 1-13, 1975.

[11] Fuzzy logic available http://en.wikipedia.org/wiki/Neural_network.

[12] MATLAB - The Language Of Technical Computing available at: http://www.mathworks.com/products/matlab/.

[13] T. Takagi and M. Sugeno, "Fuzzy identification of systems and its applications to modeling and control," IEEE Trans. Syst., Man, Cybern., vol. 15, pp. 116-132, 1985.

[14] Yuanyuan Chai, Limin Jia, and Zundong Zhang, World Academy of Science, Engineering and Technology 512009 ,"Mamdani Model based Adaptive Neural Fuzzy Inference System and its Application".

[15] Zoran Sevarac, "Neuro Fuzzy Reasoner for Student Modeling”, Department of Information Systems, School of Business Administration FON,University of Belgrade,2006 IEEE. 